From a traditional medical perspective, this is a fair and well reasoned analysis, which brings together the different aspects of the debate and shows a willingness to accommodate. But what such an approach fails to confront is the collective significance of the criticisms and their fundamental challenge to the established meaning of science and the role of medicine in society. Biomedical research is certainly capable of developing further sophisticated technology, but how far future medical progress will be judged in these terms is open to doubt.

DAVID A GREAVES

\section{Family Formation 1976}

Karen Dunnell

Office of Population Censuses and Surveys, Social Survey Division: HMSO, 1979, I I 7 pp, £7.50.

It could be argued that this report will not assist general practitioners, obstetricians or gynaecologists in the decisions - sometimes ethical ones - which they take about such fertility-related matters as contraceptive prescribing, termination of pregnancy, sterilisation, etc. In fact it might be seen as detrimental to wise decision-taking, since this is a report of a large-scale survey and therefore has the job of generalising about groups of women, whereas to take decisions about individuals one must particularise, and not stereotype. Yet, it would be a pity if this study were not read by all those interested in placing the family formation behaviour of individual women within a wider societal context. For this is a very clearly written and informative study, providing not only a great deal of descriptive data on the pregnancies, sexual behaviour and contraceptive usage, marriages and separations of a sample of over 6000 British women, but also supplementing this with data which may help one to understand trends and differences in behaviour (such as women's education, paid employment, husbands' employment and job security, views on ideal and intended family size).

Although the study is of interest to those particularly concerned with research on fertility it also has the merit of being written without the assumption that readers already possess a high degree of prior knowledge of the subject, thus making itself available to a much wider audience. The only drawback of such an approach is that the report may fail to hold the attention of those who do have prior knowledge since it frequently provides merely confirmation of already wellestablished trends or explains concepts already understood.

However, there are also new findings to report, some of which are interesting in the fact that they can be compared with the findings of previous studies (for example, the decline in family size ideals since 1967), and some in the fact that they break new ground (for example, the information provided on single women and those not legally married but cohabiting). It cannot be blamed for leaving its readers somewhat frustrated by the sense that its findings may now be out of date, for this is bound to be the case with large-scale surveys of changing behaviour.

JANET ASKHAM

Mixed Communications: Problems and Progress in Medical Care: Essays on Current Research

Twelfth Series. Gordon McLachlan (editor). Oxford University Press for Nuffield Provincial Hospitals Trust, I979, I27 pp, £4.50.

Five Years After: A Review of Health Care Research Management

Gordon McLachlan (editor). Oxford University Press for Nuffield Provincial Hospitals Trust, 1978, $85 \mathrm{pp}, £ 2.25$.

Both these books, dealing respectively with the conduct and content of medical care research, come from a charitable organisation which has a deserved reputation for the independent promotion of such worthy matters. The Nuffield Provincial Hospitals Trust has funded medical care research for many years and the results of their patronage have been regularly reported in a series of which 'Mixed Communications' is simply the latest example.

The other publication, 'Five Years After', addresses a policy issue which arouses passionate debate since it concerns the most appropriate means by which governments can finance research in the vast field of health. The topic boiled up in the early seventies with the publication of the Rothschild Report and the subsequent Green and White Papers. The idea was to design a framework which would 'make the best use of science and technology for the needs of the community as a whole'. An unexceptionable aim, one might think. But what incensed the academic community of the day was their reduction to the demeaning role of research pedlars, selling their tinkering skills to the Government who, as the wealthy customer, would only demand or buy specific products. The metaphor was not only resented but has since proved inappropriate and also very hard to implement in practice. As a result of unsatisfactory experiences with this model the whole process is now due for redesigning, which makes this publication highly relevant to a revived debate on the special theme of health service research.

This book makes especially lively reading in the first half where Professor Whitehead unabashedly relates personalities to policies in his historical review. Among the multiple problems which have arisen the key one is the sheer inability of governments or, rather, civil service administrators, to decide what is needed from medical research. The customer, in fact, is uninformed and ignorant and in no position to tell, without special advice or advertisement from the retailers themselves, what constitutes the best medical buy. Most of the book concentrates on the shaky mechanisms set up in England, in the DHSS, to get round these difficulties. It is unfortunate that the much superior Scottish arrangements do not feature here but they were described a year earlier in another Nuffield volume, 'Research in Medicine', by Sir Andrew Watt Kay.

From mixed experiences to mixed communications, we find in the other publication four very different themes, how to improve doctors' skills at talking to patients; the unmet needs of handicapped children and their parents; hospital in-patient costs and, finally, problems arising over participation in managing the health service. Charles Fletcher is eminently reasonable and humane on the matter of patients' right to know about their illness and on ways of ensuring that doctors will do better at this important task in future. Jack Hallas, in the last essay, ranges widely, but with a refreshing 